\title{
EFFECT OF VERBESINA ALTERNIFOLIA AND MENTHA PIPERITA OIL EXTRACTS ON NEWLY EXCYSTED METACERCARIA OF EUCLINOSTOMUM HETEROSTOMUM (RUDOLPHI, 1809) (DIGENEA: CLINOSTOMATIDAE) FROM NATURALLY INFECTED KIDNEYS OF TILAPIA ZILLII IN EGYPT
}

\author{
By \\ OLFAT A. MAHDY ${ }^{1}$, SAHAR Z. ABDEL- MAOGOOD ${ }^{1}$, FATEN F. MOHAMMED ${ }^{2}$ \\ AND MAI A. SALEM ${ }^{1}$ \\ Department of Parasitology ${ }^{1}$, and Department of Pathology ${ }^{2}$, Faculty of Veterinary Medi- \\ cine, Cairo University, Giza Egypt
}

\begin{abstract}
Encysted metacercariae of Euclinostomum heterostomum (EEMC) is parasitic trematodes infected kidneys of the freshwater fish (Tilapia zillii) in Egypt. The EMC causes severe pathological changes as kidney failure and even death of fish. Development a novel non-chemical approach that decreases the need of anthelmintic drugs, proved to be the only realistic strategy to avoid drug resistance especially with biodegradable eco-friendly plant extracts.

In the present study, T. zillii infected with EEMC was $14.5 \%$. Histopathology of the tissue showed marked glomerular congestion with interstitial congestion, hemorrhages, vacuolization and necrosis of tubular epithelium with activation of melanomacrophage center.

The anthelmintic activity of Verbesina alternifolia, Mentha piperita oil extracts on newly excysted metacercariae (EExMC) of Euclinostomum heterostomum was evaluated in vitro. The $\mathrm{LC}_{50} \% \& \mathrm{LC}_{100} \%$ for $V$. alternifolia was $400 \mathrm{ppm} / 12 \mathrm{hrs}$ and $600 \mathrm{ppm} / 24 \mathrm{~h}$, respectively. $\mathrm{LC}_{50} \%$ of M. piperita was $1000 \mathrm{ppm} / 24 \mathrm{hrs}$. Doses lower did not cause mortality of exposed EExMC.

Exposure to both plants caused marked irreversible alteration in tegumental ultrastructure of the exposed EExMC led to mortality. The effect increased with increase in concentration and exposure time. SEM examination of $V$. alternifolia died EExMC showed ill distinct collar like rings, and lack of transverse ridges which appear highly corrugated edematous tegument. Collar ring in M. piperita exposed group was ill distinct with several blebs around ventral sucker and body tegument edematous.
\end{abstract}

Keywords: Egypt, E. heretostomum, Verbesina alternifolia, Mentha piperita, SEM, Histo-pathology, Kidney, T. zillii.

\section{Introduction}

Among the parasites, trematodes are the dominant group that causes retarded growth, morbidity, and mortality especially in juvenile fishes. It has been estimated that about 30000 species of helminthes are parasites of fishes (Williams and Jones 1994). In addition to the huge economic loss they cause, at least 50 species of these helminths are potentially zoonosis (Deardorff, 1991). The hemophagic clinostomid trematode Euclinostomum heterostomum (Rudolphi, 1809) is a common parasite of piscivorous birds in many regions of Africa (Yamaguti, 1971; Kannev et al, 2002a; Wang et al, 2017). In Egypt, the larval stage of this parasite infected the kidney of its second intermediate host ( $\mathrm{Ti}^{-}$ lapia sp.) as encysted progenetic metacercariae (Taher, 2009).

The major effect caused by Verbesina may be due to high levels of nitrates and galegine (Taher et al., 2012) and due to phyto-constituents of Verbesina as terpenoids, flavonoids and aromatic compounds (Song et al, 2009, Sindhu et al, 2010). Menthol and menthone are the main components of Mentha piperita (Mahboubi and Kazempour, 2014).

Histological studies of various pathogenic agents in different fish species have been reported and proposed as an efficient method to asses fish health, such as chemicals and pesticides (Troncoso-Ponce et al, 2011) and helminthes parasites (Shareef and Abidi 2012). Apart from the life cycle 
and morphometry elucidated by some researchers, no study has been found that reports on the effects of plant oil extract alternation on the ultra structure tegument on the parasite and the pathogenecity and damage exerted on the tissues of fish during infection with E. heterostomum.

The present work aimed to study the effect of two plant oil extract; Verbesina alternifolia, and Mentha piperita on newly EExMC infection by using SEM for alternation of tegumental and histopathological changes caused by EEMC in infected $T$. zillii.

\section{Materials and Methods}

Sampling: Forty hundred and fifty freshwater fishes, mainly Tilapia zillii were caught by fisherman from natural Nile resources at Giza governorate, Egypt during the period from January-December 2016.

The collected fish were kept alive until examination at the parasitology laboratory, Faculty of Veterinary Medicine, Cairo University, where weight, total length and visual inspection to detect macroscopically visible parasites. The Euclinostomum metacercariae, mostly located in the peritoneum covering the kidney surface, were excysted and fixed in $70 \%$ ethanol for morphological study. Other number of fresh newly excysted metacercariae of collected parasites exposure to plants oil extracts.

Morphological identification: Whole mounts were made of 20 specimens clarified with Amman's lacto phenol, among which 10 were also stained by Semichons acetocarmine (Pritchard and Kruse, 1982). Parasites were identified based international keys for the family Clinostomidae (Kannev et al, 2002a, b). The EExMC was identified as Euclinosto-mum heterostomum after Fischthal and Kuntz (1963) and Ukoli (1966). The morphological features were taken by a digital camera (Sony, 3.0 MP Japan) attached to an inverted microscope (Olymbus, Japan).
Plant oil extract: Two plants oil extracts; Verbesina alternifolia and Mentha piperita were prepared (Salama et al, 2012).

Fresh active EExMC were washed three times in PBS solution. The EExMC ( $n=10 /$ well) were exposed to a series of upgrading concentrations of each plant extract oil. Each experiment sets contained two replicates each of 10 EExMC. Control group in solvent as well as in PBS was associated with each exposure time. The bioassay was done according to WHO (1996) guidelines. All experiments were done under the same laboratory conditions. At the end of each exposure time, tested solution was removed; EExMC were washed for five times in PBS, left for another 3 hours, mortality $\%$ were evaluated by counting number of dead EExMC from exposed one (Taher et al, 2012).

The effect of plant extract on EExMC tegument on motor activity was classified as: live movement, slow movement, slow movement with damaged tegument, and/or dead (Panic et al, 2013). Efficacy of plant extracts activity was assessed by comparing the number of affected EExMC in each exposed group with that corresponding to control group.

Scanning electron microscopy (SEM): For SEM, EExMC were obtained from vitro assays study and control prepared by serial washing in saline solution and fixed in $2.5 \%$ glutaraldehyde (Colwell et al, 2007). Specimens were then dehydrated in ascending ethanol, dried in $\mathrm{CO} 2$ critical point drier (Autosamdri-815, Germany), glued over stubs and coated with $20 \mathrm{~nm}$ (Gold in a sputter coater; Spi-Module Sputter Coater, UK). Specimens were examined and photographed with SEM at magnifications of $35 \mathrm{X}$ to $500 \mathrm{X}$ (JSM 5200, Electron prob Microanalyzer, Jeol, Japan) at Faculty of Agriculture, Cairo University.

Histopathological study: Five specimens from each exposed and control groups of EEMC infected fish were fixed in $10 \%$ 
buffered formalin solution, processed for histological sectioning, stained with haematoxylin and eosin (Humason, 1979) and examined by light microscope for pathological changes kidney.

\section{Results}

Of 447 of $T$. zillii specimens collected, 65 were infected with Euclinostomum meta-cer-cariae, with a rate of $14.5 \%$. Cysts were encapsulated in body cavity and kidneys. The peritoneum of the kidney was most favorable site of infection whereas least one was the body cavity with metacercariae varied from1-17cyst/fish (Pl. 1a).

Infection caused severs destruction in the fish tissue. Kidney with EMC of E. heterostomum showed parasite with intact normal internal structure enclosed by thick dense fibrous capsule frimalt attached to renal tissue. Also, cyst wall was incorporated with renal interstium and glomerular structures with intense inflammatory cell infiltration and extending into the adjacent renal tissue. Marked glomerular congestion with interstitial congestion, hemorrhages, vacuolization and necrosis of tubular epithelium with active melanomacrophage center (Fig. 1 \& 2a, b,c).

Exposure of EExMC to different concentration of $V$. alternifolia oil extract caused mortality associated with irreversible degenerative changes in cuticle, oral and ventral suckers. The degenerative effect increased with the increase of dose and exposure time. At 200- 400ppm/4-6hrs, anterior region showed slow movement, while the posterior one was paralyzed. At $400 \mathrm{ppm} / 10 \mathrm{hr}$, reduced movement and tissue damages were observed. Died worms showed opaque grayish color with opaque appearance and confirmed shape. The mean $\mathrm{LC}_{50}$ and $\mathrm{LC}_{100}$ of the oil extract reached to $400 \mathrm{ppm} / 12 \mathrm{hrs} 600 \mathrm{ppm} / 24 \mathrm{hrs}$ and died EExMC with shrinkage and corrugated cuticle.

Exposure of EExMC under the same conditions to different concentrations of $M$. piperita oil extract had no effect at concentration from 200 to 600 ppm and 6$24 \mathrm{hrs}$ exposure periods. Mortality started as $10 \%$ in those exposed to $800 \mathrm{ppm} / 12 \mathrm{hr}$ increased to $30 \%$ after $24 \mathrm{hrs}, 50 \%$ mortality (LC50\%) when exposure to $1000 \mathrm{ppm} /$ $24 \mathrm{hrs}$. Tested concentrations failed to induce more mortality to the experimental end. Died worms showed no movement associated with tegumental damage.

Control group: Neither changes in movement nor in tegumental of the EExMC in PBS were noticed nor they remained viable to the experimental end.

SEM: EExMC in control showed tegument (after various incubation times) to be normal (Pl. 2-5a). Oral sucker was smooth collar-like rings, covered by ridges and tegumental surface was distinct ventral transverse striation at ventral sucker posteriorly (Pl. 2b). Ventral sucker exhibited was sponge-like with normal tegument margins (Pl. 4b). Body posteriorly showed normal tegument (Pl. 5b).

SEM in EExMC exposed to Verbesina oil for 400ppm/12hrs showed marked edematous tegument at body anterior ventral surface (Pl. 2b), and, distortion of oral and ventral suckers with disappearance of collar like rings around oral sucker (Pl. 3b). Ventral sucker showed deformed, more edematous and thick (Pl. 4b) and posterior tegument surface was clearly edematous (Pl. 5b).

SEM in EExMC exposed to $M$. piperita oil for $1000 \mathrm{ppm} / 24 \mathrm{hrs}$ was high swelled, edematous with disorganization of suckers and tegument deformity. Dead EExMC showed complete tegumental changes ( $\mathrm{Pl}$. 2c). Oral sucker showed disappeared of the two collar-like rings with highly edematous tegument (Pl. 3c). Tegumental surface was ill distinct ventral transverse striation. Irregular swellings, or blebs were particularly concentrated around ventral sucker (Pl. 4c) and edematous posterior body tegument (Pl. 5c).

Verbesina oil extract gave marked effect on parasites inside the kideny (Fig. $1 \& 2$ d, 
e, f). kidney showed edema of internal structures and loose attachement between cyst wall and renal tissue. Edema of outer fibrous layer toward renal tissue resulted in loose attachement of cyst to renal tissue degeneration and edema of fibrous tissue cyst wall and interstitial edema with EGCs infiltration with minimal necrosis of tubular epithelium.

\section{Discussion}

Parasitic digeneans of family Clinostomidae are widely distributed, with trematode flukes of the genus Euclinostomum found as common parasites of piscivorous birds in many regions of world. Metacercariae may affect the growth and survival of fish, or may disfigure fish so that they lose their market value as either food or an ornamental product (Paperna, 1991). Several strategies have been proposed as screening methods for new drugs with anthelmintic potential based on in vivo models (Gonçalves et al, 2014) in which obtaining the worms requires the use of infected animals. In this context, the most recent research indicates that species of the genus Echinostoma satisfy this need (Fried and People, 2009; Keiser, 2010). Previous results showed that $E$. paraensei is a useful in vitro and in vivo model for both biological and therapeutic studies (Maldonado et al., 2005; Souza et al., 2013). Our previous results showed that Prohemistomum vivax (adult trematode) is a useful in vitro and in vivo model for both biological and therapeutic studies (Ibrahim and Mahdy, 2017). In the present study, compared with exposure the EExMC to both plants oil extract, at high concentrations (400ppm/12hrs) during this exposure periods, causes decreased movement and tegument change and lethal dose fifty LC50\% was occur. The similar result to those recorded by Souza et al. (2017) when exposed newly excysted metacercariae of Echinostoma paraensei in vitro to artesunate in emphasize that these effects are both time- and dose-independent.
In order to evaluate the in vitro use of EExMC, the present study compared ultrastructure morphological alterations caused by $V$. alternifolia and $M$. piperita, with those observed in excysted metacercariae, reporting new qualitative and quantitative morphological changes.

In the present results, body tegument damage and mortality was higher concentrations after 12 hours' incubation. The severe damage was at anterior region around the oral sucker, with high swelling, including disorganization of the suckers and ultra-structure tegument deformity. This agreed with Souza et al. (2017). Also, the present results went others who reported tegument morphological alterations especially EExMC exposed to Mint. Also, blebs, furrowing, swelling, disruption and deformity resulted by artemisinin derivatives in vitro on Schistosoma mekongi (Jiraungkoorskul et al, 2006), Fasciola gigantica (Diab et al, 2010) and Echinostoma caproni (Keiser et al, 2006).

In the present study, the integrity and function of the tegument were critical and related to survival of EExMC. In Egypt, Verbesina alcoholic extracts as molluscicidal and/or mosquito larvicidal activities by Verbesina corresponded to high levels of nitrates and galegine (Taher et al, 2012). The physiological processes might be impaired, although the mechanism of action of the present plants extracts, actedagainst $C$. phalacrocoracis was elucidated, the possible mechanism and $V$. alternifolia was strong and highlighted the presence of EExMC than the effect of $M$. piperita due to Menthol was the main substance of composition and confirmed to display anthelmintic activities (Girme et al, 2006).

Eskes et al. (2009) stated that research must be carried out with alternative techniques to provide the same level of information as that in experiments on animals. The present study went in line with Eskes et al. (2009) as the effects were the same 
as those of Ultrastructure tegumental changes with EExMC.

The present histopathological study, revealed histozoic parasite stages in fish kidney. Infection of $T$. zillii by EEMC decreased fish immunity, allowing other pathogens infections. E. heterostomum infections were reported in many fish species, including Tilapia (Dönges, 1974, Britz et al, 1985, Olurin and Somorin 2006). Jhansilakshmibai and Madhavi (1997) reported that E. heterostomum infected the liver and kidney of $C$. punctata. But, in the present study, parasite was encysted only in the peritoneal of kidney. The histo-architectural alterations were induced by $E$. heterostomum with intact normal internal structures and marked glomerular congestion, vacuolization and necrosis of tubular epithelium with activation of melanomacrophage center. The agreed with Shareef and Abidi (2015) in $C$. punctata infected kidney. Also, in exposed to Verbesina at 400ppm/12hrs showed edema of internal structures of $E$. heterostomum.

\section{Conclusion}

This could be the first time to show the in vitro anthelmintic activity of $V$. alternifolia and $M$. piperita against EExMC. The $\mathrm{LC}_{50} \%$ for $V$. alternifolia and $M$. piperita was 400ppm/12hrs and $1000 \mathrm{ppm} / 24 \mathrm{hrs}$, respectively. The $V$. alternifolia showed anthelmintic activity higher than $M$. piperi$t a$ for the exposed EExMC.

The outcome data showed that the newly excysted metacercariae of Euclinostomum heterostomum constituted a good model to study in vitro contribution and to find out natural plant extracts efficiecy as anthelmintic agents

\section{References}

Britz, J, Van As, JG, Saayman, JE, 1985: Occurrence and distribution of Clinostomum tilapiae Ukoli, 1966 and Euclinostomum heterostomum (Rudolphi, 1809) metacercarial infections of freshwater fish in Venda and Lebowa, southern Africa. J. Fish Biol. 26, 1:21-8.
Colwell, MA, Hurley, SJ, Hall, JN, Dinsmore, SJ, 2007: Age-related survival and behavior of Snowy Plovers chicks. Condor 109:63847.

Deardorff, Alan V, 1991: Trade Policy of the Reagan Years. In: The Economic Legacy of the Reagan Years: Euphoria or Chaos? By Sahu, AP, Ronald, L, Tracy, eds., New York: Pager Publishers.

Diab, TM, Mansour, HH, Mahmoud, SS, 2010: Fasciola gigantica: Parasitological and scanning electron microscopy study of the in vitro effects of ivermectin and/or artemether". Exp. Parasitol. 124:279-84.

Dönges, J, 1974: Life cycle of Euclinostomum heterostomum (Rudolphi, 1809) (Trematoda: Clinostomatidae). Int. J. Parasitol. 4:7990.

Eskes, C, Sá-Rocha, VM, Nunes, J, Presgrave, O, Carvalho, D, et al, 2009: Proposal for a Brazilian Centre on Alternative Test Methods. Altex 26:265-8.

Fischthal, JH, Kuntz, RE, 1963: Trematode parasites of fishes from Egypt. Part III. Six new Hemiuridae. Proceed. Helminthol. Soc. Washington, 30:78-91.

Fried, B, Peoples, RC, 2009: Longevity of Echinostoma caproni in Bulb/c mice. J. Helminthol, 82:95-6.

Girme, AS, Bhalke, RD, Ghogare, PB, Tambe, VD, Jadhav, RS, et al, 2006: Comparative In vitro Anthelmintic Activity of Mentha piperita and Lantana camara from Western India. Dhaka Univ. J. Pharm. Sci. 5, 1/2:5-7.

Gonçalves, RB, Scherer, VL, Oliveira, PS, 2014: The orchid bees (hymenopTera, apidae, euglossina) in a forest fragment from western paraná state, brazil. Volume 54(6):63-68.

Humason, GL, 1979: Animal Tissue Techniques. $4^{\text {th }}$ ed. WH, Freeman \& CO, San Francisco.

Ibrahim, TB, Mahdy, OA, 2017: In vitro and In vivo Effects of Carica papaya Seed Extract on the Ultrastructure of the Tegument of Prohemistomum vivax (Sonsino, 1892) (Trematoda: Prohemisto-matidae). Int. J. Zool. Res. 13, 1:45-53.

Jhansilakshmibai, K, Madhavi, R, 1997: $E u$ clinostomum heterostomum (Rudolphi, 1809) (Trematoda): life-cycle, growth and development of the metacercaria and adult. Syst. Parasitol. 38, 1:51-64. 
Kannev, I, Radev, V and Fried, B, 2002a: Family Clinostomidea Lühe, 1901. In:Gibson DI, Jones A, Bray RA (eds) Keys to the trematoda, Vol 1. CAB International and the Natural History Museum, London.

Kannev I, Radev V, Fried B, 2002b: Superfamily Clinostomoidea Lühe, 1901. In: Gibson DI, Jones A, Bray RA (eds) Keys to the trematoda, Vol 1. CAB International and the Natural History Museum, London.

Keiser, J, 2010: In vitro and in vivo trematode models for chemotherapeutic studies. Parasitol. 137:583-603.

Keiser, J, Brun, R, Fried, B, Utzinger, J, 2006: Trematocidal activity of praziquantel and artemisinin derivatives: in vitro and in vivo investigations on adult Echinostoma caproni. Antimicrobial. Agents Chemother. 50:8035.

Mahboubi, M, Kazempour, N, 2014: Chemical composition and antimicrobial activity of peppermint (Mentha piperita L.) essential oil. Songklanakarin J. Sci. Technol. 36, 1:83-7.

Maldonado, MM, Carmona, C, Vela'squez, Z, Puig, A, Cruzado, A, 2005: Siliceous sponges as a silicon sink: An overlooked aspect of benthopelagic coupling in the marine silicon cycle. Limnol. Oceanogr. 50, 3:799-809.

Olurin, KB, Somorin, CA, 2006: Intestinal Helminths of the fishes of Owa stream, southwestern Nigeria. Res. J. Fish. Hydrobiol.2:1:69.

Panic, G, Ingram, K, Keiser, J, 2013: Development of an in vitro drug sensitivity assay based on newly excysted larvae of Echinostoma caproni. Parasit. Vect. 23:237-45.

Paperna, I, 1991: Diseases caused by parasites in the aquaculture of warm water fish. Ann. Rev. Fish Dis.1:155-94.

Pritchard, MH, Kruse, GO, 1982: The collection \& preservation of animal parasites. Tech. Bull. No.1. The Harold W. Manter Laboratory, University of Nebraska Press.

Salama, MM, Taher, EE, El-Bahy, MM, 2012: Molluscicidal and Mosquitocidal Activities of the Essential oils of Thymus capitatus Hoff. et Link. and Marrubium vulgare L. Rev. Inst. Med. Trop., São Paulo, 54, 5:281-6.

Shareef, PAA, Abidi, SMA, 2012: Incidence and histopathology of encysted metacercaria of Clinstomum complnatum (Digenea: Clintimidae) in Chana punctatus and its development in experimental host. Asian Pac. J. Trop. Biomed, 2, 6:421-6.

Shareef, PAA, Abidi, SMA, 2015: Studies on the epidemiology and histopathology of Euclinostomum heterostomum (Trematoda; Digenea) infection in Channa punctata from North India. Arch. Pol. Fish. 23:133-40.

Sindhu, RK, Vasudeva, N, Sharma SK, 2010: Pharmacognostical \& preliminary phytochemical investigations on Verbesina encelioides Benth. Roots. J. Herb. Med. Toxicol. 4:113-8.

Song, A, Wang, Y, Liu, Y, 2009: Study on the chemical constituents of the essential oil of the leaves of Eucalyptus globulus Labill from China. Asian J. Tradit. Med. 4:134-40.

Souza, JG, Garcia, J, Neves, RH, MachadoSilva, JR, Maldonado, 2013: A. In vitro excystation of Echinostoma paraensei (Digenea: Echinostomatidae) metacercariae assessed by light, morphometry and confocal laser scanning microscopy. Exp. Parasitol. 135:701-7.

Souza, MT, Amaral, W, Pascoalino, J, Oliveira, RA, Bizzo, HR, Deschamps, C, 2017: Chemical composition of the essential oils of Baccharis species from southern Brazil: a comparative study using multivariate statistical analysis. J. Essent. Oil Res. 6:1-7.

Taher, GA, 2009: Some studies on metacercarial infection in Oreochromis niloticus in Assiut governorate and their role in transmission of some trematodes to dogs. Assuit Univ. Bull. Environ. Res. 12, 1:63-79.

Taher, E, Mahmoud, N, Mahmoud, M, 2012: Laboratory evaluation of the effect of Egyptian native plants against some parasitic vectors. Turk. Parazitol. Derg. 36:160-5.

Troncoso-Ponce, MA, Kilaru, A, Cao, X, Durrett, TP, Fan, J, et al, 2011: Comparative deep transcriptional profiling of four developing oilseeds. Plant J. 68, 6:1014-27.

Ukoli, FM, 1966: On the life history, growth and development from the metacercarial stage to adulthood, of Clinostomum tilapiae. J. Helminthol. 40, 1:215-26.

Wang, ML, Chen, HY, Shih, HH, 2017: Occurrence and distribution of yellow grub trematodes (Clinstomum complnatum) infection in Taiwan. Parasitol. Res. 116:1761-71.

WHO, 1996: Report of WHO in formal consultation on the evaluation and on the testing of insecticides, CTD/WHO PES /IC/96.1, 69. 
Williams and Jones 1994: Parasitic worms of fish. Folia Parasitologica, 41:38-44.
Yamaguti, S, 1971: Synopsis of Digenetic Trematodes of Vertebrates. Keigaku, Tokyo, Vol. I, \& Vol. II.

\section{Explanation of plates}

Plate 2: SEM of ventral tegument of E. heterostomum a) A control non exposed EExMC showing distinct normal collar-like rings, oral sucker (os), ventral sucker (vs). b) Exposed EExMC to $V$. alternifolia extract showed corrugated tegument with disfigured and distortion of oral \&ventral suckers c) Exposed EExMC to Mint oil extract showed edematous tegument with disfigured and distortion of both suckers.

Plate 3: SEM of oral sucker of E. heterostomum a) A control non exposed EExMC showing normal collar-like rings (CL) distinct smooth tegument (st). b) Exposed EExMC to V. alternifolia extract showed disappearance of CL and sever corrugated tegument (ct) around the oral sucker c) Exposed EExMC to Mint oil extract showed highly edematous oral sucker (ot) and shrinkage of the oral sucker (os).

Plate 4: SEM of ventral sucker of E. heterostomum a) A control non exposed EExMC showing normal sucker. b) Exposed EExMC to $V$. alternifolia extract showed thicker folds and edematus c) Exposed EExMC to Mint extract and appear of numerous blebs around ventral sucker (arrows).

Plate 5: SEM of posterior tegumental surface of E.hetrostomum a) A control non exposed EExMC showing normal smooth cuticle. b) Exposed EExMC to V. alternifolia extract showed edematous tegument. c) Exposed EExMC to Mint extract showed edematous tegument.
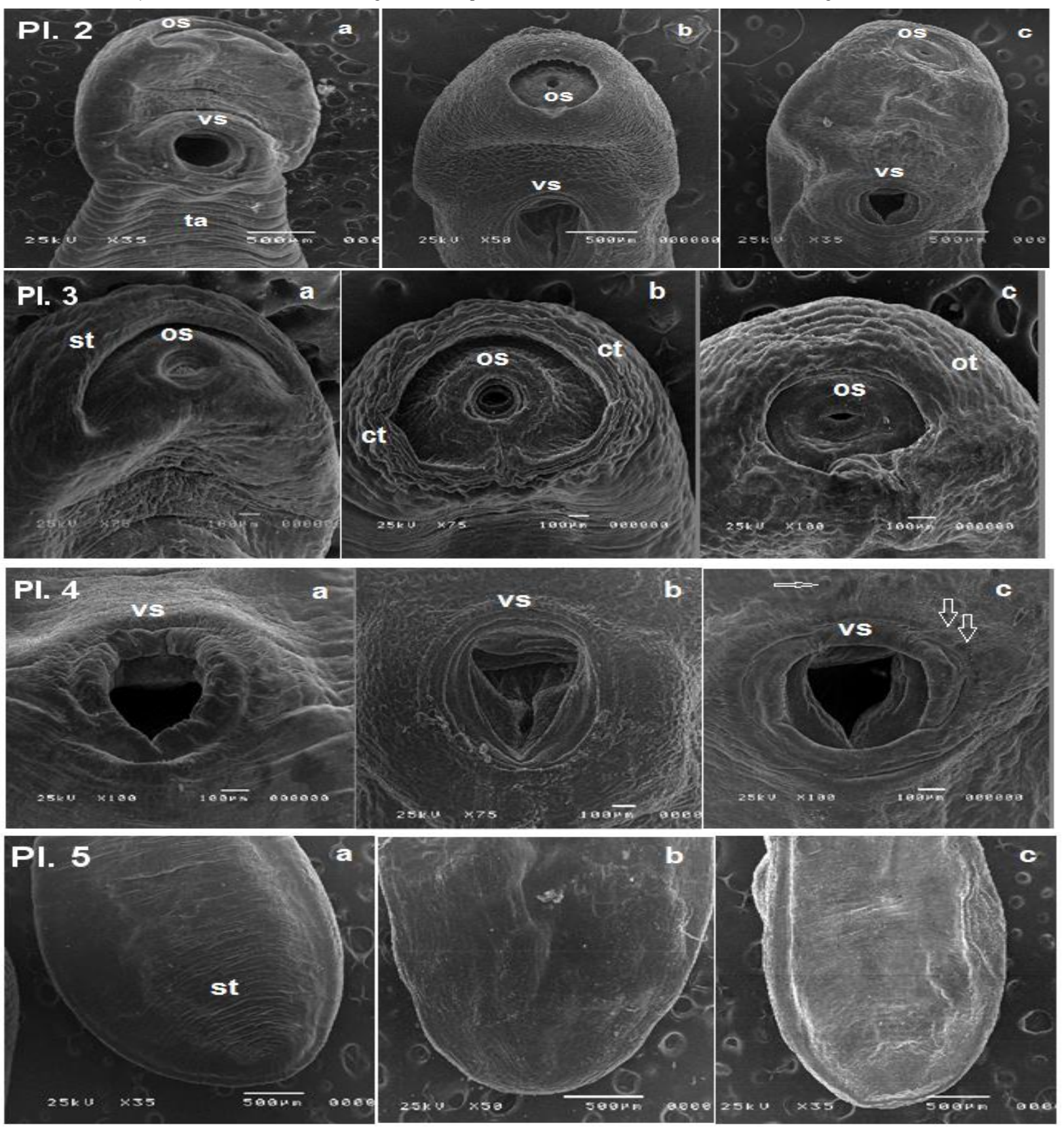


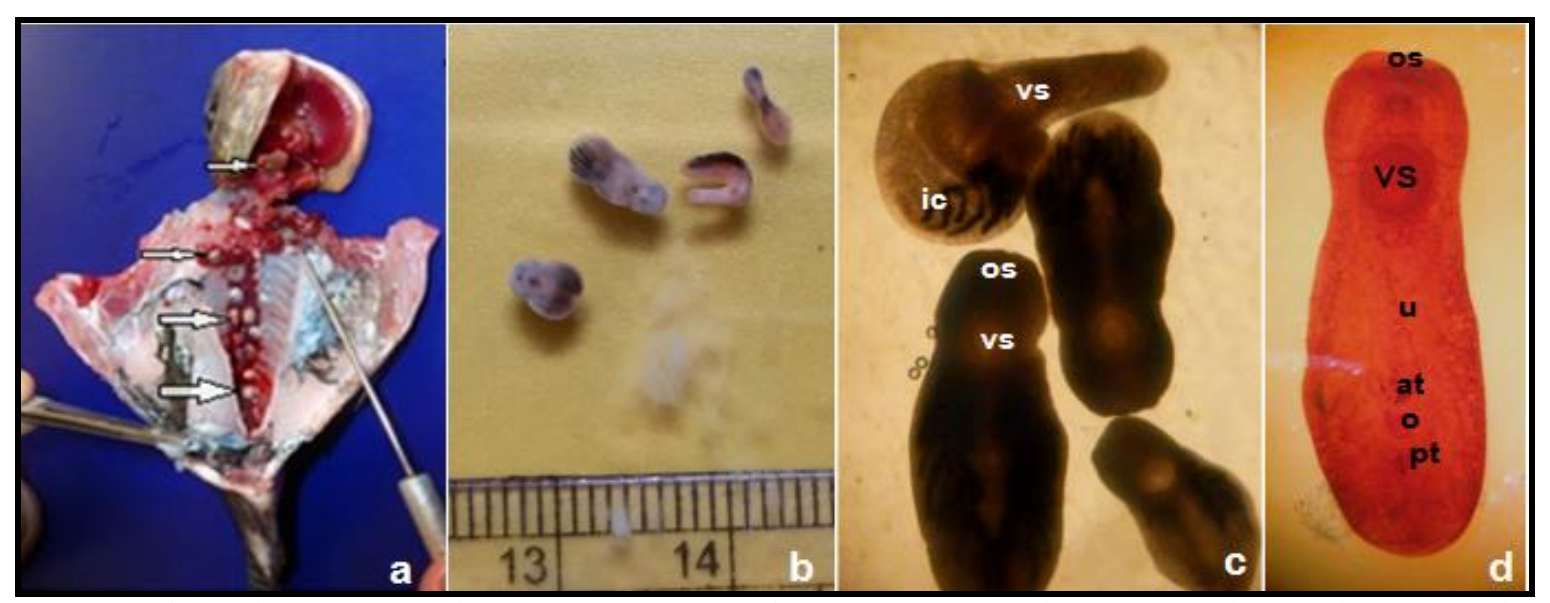

Plate 1; a) Infected kidney of T.zillii with encysted metacercaria of E. heterostomum showing 17 EEMC in the peritoneum covering kidney and tissues ( thick arrow in kidney and thin arrow in other tissues). B-c). Newly excysted metacercariae of E. heterostomum fresh specimens, showing distinct oral andventral sucker (os \& vs) and branched intestinal cecae (ic). d) Stained E. heterostomum, showing distinct; oral sucker (os),ventral sucker (vs), testes; anterior testis (at) and posterior testis(pt) and (o).

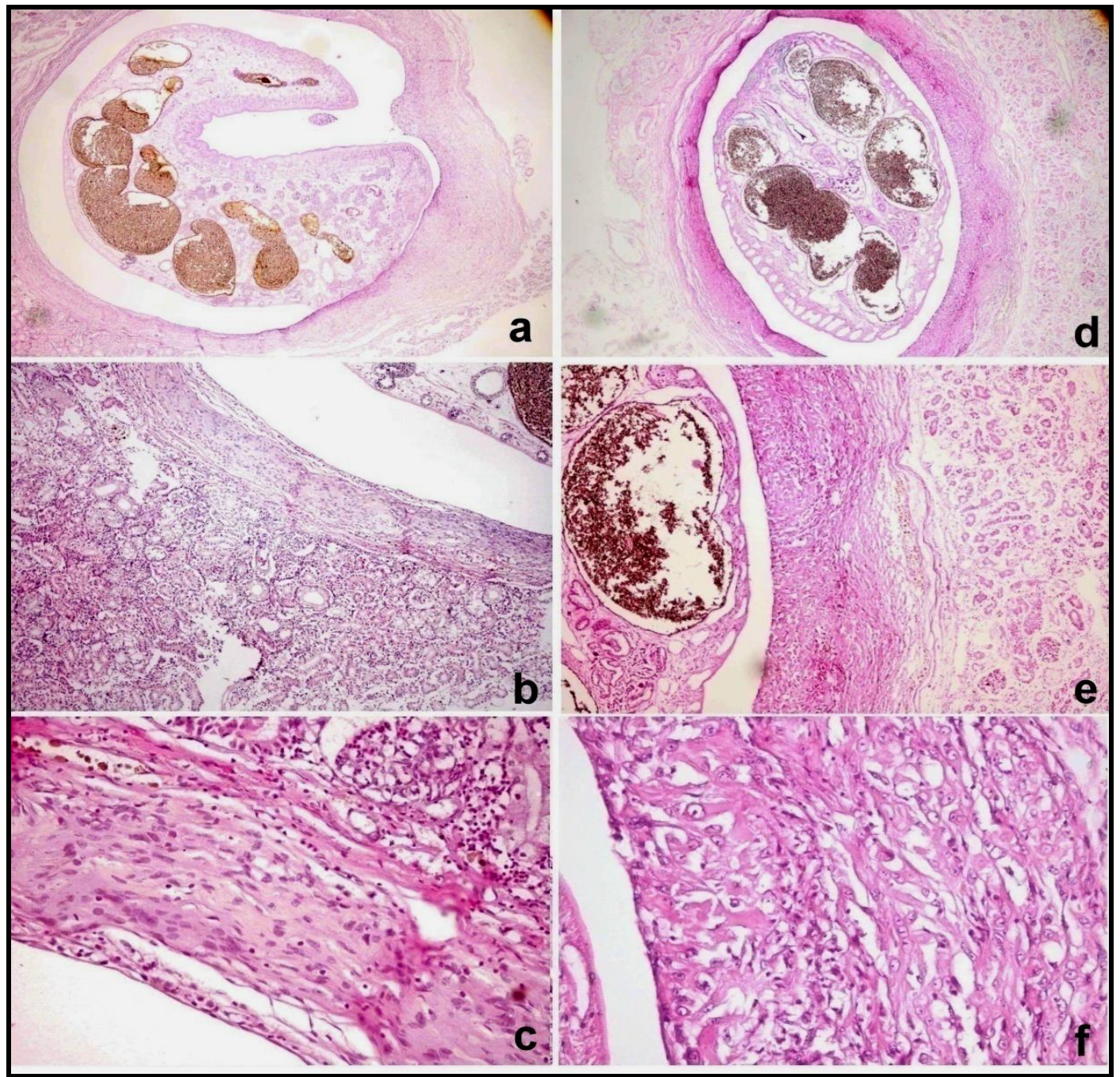

Fig.1: (a-c) Histological section of kidney control group showing; a) presence of large encysted metacercaria enclosed by thick dense fibrous capsule frimalt attached to renal tissue and incorportaed into renal tissure structures (X40). b) control group showing dense fibrous cyst wall incorporated with renal interstium (X100).c) incorporation of glomerular structures in structure of connective tissue of cyst wall associated with intense inflammatory cell infiltration in cyst wall and extending into adjacent renal tissue, (X400). (df)Histological section of kidney exposed group to Verbesina oil plant extract showing d)presence of large encysted metacercaria enclosed by fibrous capsule with loose attachement between cyst wall and renal tissue (X40). e) edema of outer fibrous layer to renal tissue resulting in loose attachement of parasitic cyst to renal tissue (X100). f) degeneration and edema of fibrous tissue wall (X400). 


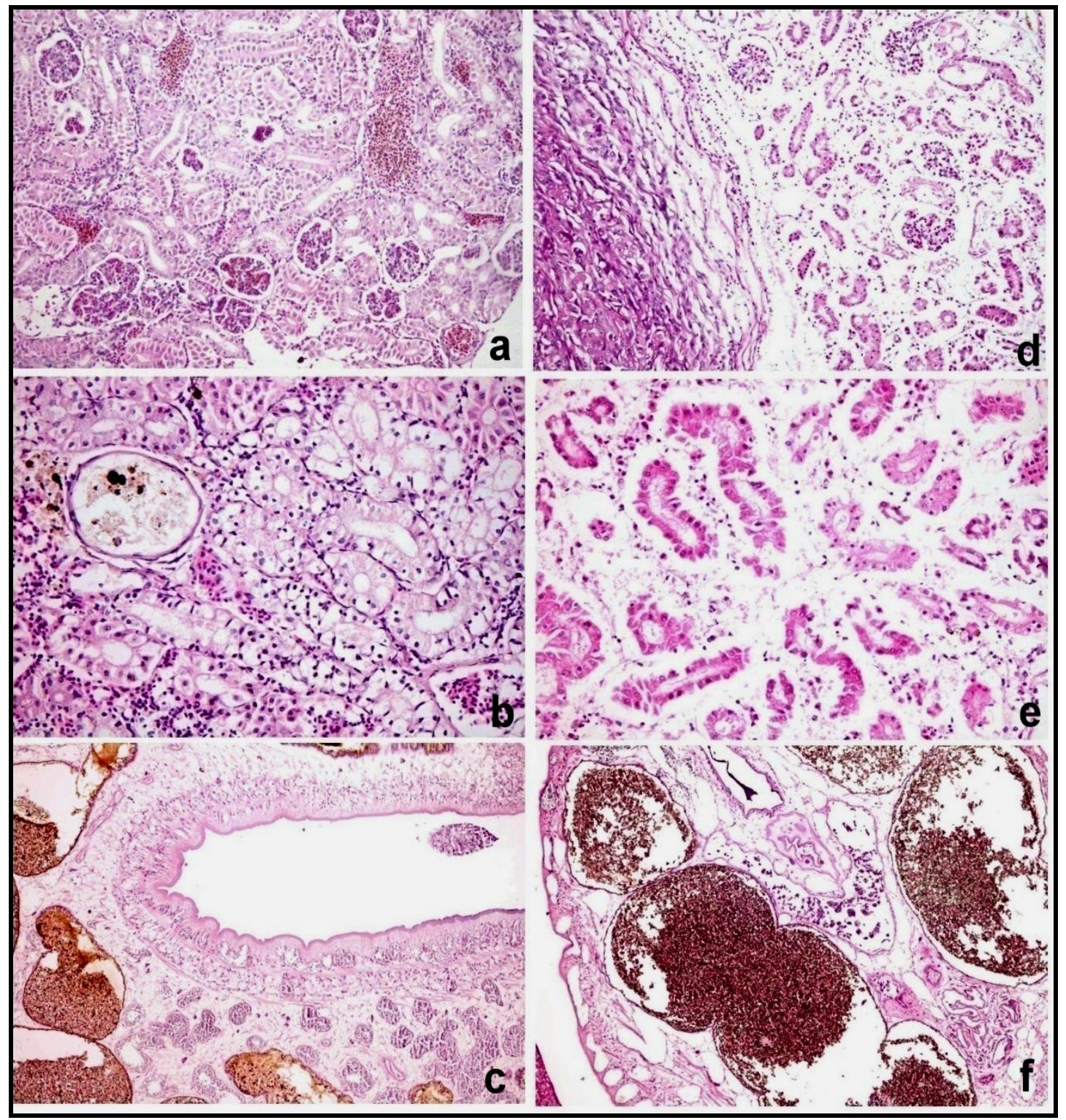

Fig.2: (a-c) Histological section of kidney control non exposed group showing;

a)marked glomerular congestion with interstitial congestion and hemorrhage (X200). b) vacuolization and necrosis of tubular epithelium with activation of melanomacrophage center (X200). c) Euclinostomum heterostomum with intact normal internal structures (X100). (df) Histological section of kidney exposed group showing d) Exposed group showing massive edema of cyst wall that was extended into adjacent renal interstitium (X100). e) interstitial edema with EGCs infiltration with minimal necrosis of tubular epithelium (X200). f) edema of internal structures (X100). 